\title{
Cortical Activation Through Passive-Motion Functional MRI
}

\author{
(iD) A.F. Choudhri, R.M. Patel, A. Siddiqui, M.T. Whitehead, and J.W. Wheless
}

\begin{abstract}
BACKGROUND AND PURPOSE: Functional brain mapping is an important technique for neurosurgical planning, particularly for patients with tumors or epilepsy; however, mapping has traditionally involved invasive techniques. Existing noninvasive techniques require patient compliance and may not be suitable for young children. We performed a retrospective review of our experience with passive-motion functional MR imaging in anesthetized patients to determine the diagnostic yield of this technique.
\end{abstract}

MATERIALS AND METHODS: A retrospective review of patients undergoing passive-motion fMRI under general anesthesia at a single institution over a 2.5-year period was performed. Clinical records were evaluated to determine the indication for fMRI, the ability to detect cortical activation, and, if present, the location of cortical activation.

RESULTS: We identified 62 studies in 56 patients in this time period. The most common indication for fMRI was epilepsy/seizures. Passive-motion fMRI identified upper-extremity cortical activation in 105 of 119 (88\%) limbs evaluated, of which 90 (86\%) activations were in an orthotopic location. Lower-extremity cortical activation was identified in 86 of 118 (73\%) limbs evaluated, of which 73 ( $85 \%$ ) activations were in an orthotopic location.

CONCLUSIONS: Passive-motion fMRI was successful in identifying cortical activation in most of the patients. This tool can be implemented easily and can aid in surgical planning for children with tumors or candidates for epilepsy surgery, particularly those who may be too young to comply with existing noninvasive functional measures.

T

he criterion standard for presurgical brain mapping has typically been intraoperative cortical stimulation mapping and the Wada test. ${ }^{1-4}$ Both methods are invasive procedures, and their efficacy and superiority over other mapping procedures have become less clear with advances in noninvasive brain-mapping techniques, ${ }^{4-12}$ with some studies showing that these alternative methods are comparable to stand-alone and/or adjunct techniques. ${ }^{9-18}$ Blood oxygen level-dependent functional MR imaging is an increasingly used imaging technique in the clinical setting. Since the early 1990s, it has been used to study brain function

Received September 4, 2014; accepted after revision February 13, 2015.

From the Departments of Radiology (A.F.C., A.S., M.T.W.), Neurosurgery (A.F.C.), and Pediatrics (J.W.W.) and College of Medicine (R.M.P.), University of Tennessee Health Science Center, Memphis, Tennessee; Le Bonheur Neuroscience Institute (A.F.C., A.S., M.T.W., J.W.W.), Le Bonheur Children's Hospital, Memphis, Tennessee; and Department of Radiology (M.T.W.), Children's National Medical Center, Washington, DC.

Paper previously presented at: Annual Meeting of the American Society of Neuroradiology, April 25-30, 2015; Chicago, Illinois.

Please address correspondence to A.F. Choudhri, MD, Department of Radiology, Le Bonheur Children's Hospital, 848 Adams Ave, G216, Memphis, TN 38103; e-mail: achoudhri@uthsc.edu; @AsimChoudhriMD

http://dx.doi.org/10.3174/ajnr.A4345 in healthy individuals and particularly for surgical planning in patients with brain tumors or epilepsy. , 4,17,19-22 $^{\text {This imaging }}$ technique maps areas of cortical activation via changes in blood flow to metabolically active brain regions during cortical activation, typically secondary to specific motor, language, and visual tasks. fMRI provides a number of benefits: it is noninvasive, it is a useful tool for presurgical evaluation for invasive procedures that involve high risk, ${ }^{2,4,17,19,20,23,24}$ and it can also assess the current function of patients with brain lesions or previous brain surgery. ${ }^{20,25}$ Clinically, it is performed as a task-based technique that requires the patient to cooperate and keep all other body movements to a minimum. Incomplete compliance limits the utility of this technology and introduces risk for spurious results. Compliance with the tasks and remaining still is a particular concern in young children and patients with developmental or acquired cognitive deficits. ${ }^{26,27}$ Even children who can perform the task during training sessions may not be able to comply in the MR imaging scanner. ${ }^{27}$

A strategy that allows this information to be obtained from subjects who are unable to cooperate is to perform a similar fMRI task under sedation. fMRI of sedated patients performed with passive motion of the extremities has been successful in some 
reports. ${ }^{15,23,24,28,29}$ The goal is to map the motor cortex while removing the need for task compliance and reducing or eliminating concerns for patient motion. ${ }^{23,24,28}$ We performed a retrospective review of our institution's 2.5-year experience with passive-motion fMRI to assess the feasibility and reliability of this imaging technique.

\section{MATERIALS AND METHODS}

This Health Insurance Portability and Accountability Actcompliant retrospective review was performed after institutional review board approval. We performed a retrospective chart review of all functional MR imaging scans performed at a single pediatric academic medical center over a consecutive 2.5-year period (August 2012 to December 2014), representing the first 2.5 years of a passive-motion fMRI program in which a particular acquisition technique and processing software were used.

\section{Functional MR Imaging}

Functional MR imaging was performed on a 3T MR imaging scanner (HDxt; GE Healthcare, Milwaukee, Wisconsin) by using an 8-channel head coil. Blood oxygen level-dependent fMRI was acquired by using an echo-planar imaging sequence performed with a TR of 3000 ms. Eighty-three EPI acquisitions were performed for each functional paradigm for a scan time of 4 minutes 9 seconds. The initial 3 sets of images, acquired during the first 9 s, were discarded, and the subsequent 80 EPI acquisitions were analyzed. A block design was used for functional tasks, with 15-s alternations between the tasks and rest encompassing 5 TR intervals. For the passive-motion functional MR imaging, the neuroradiologist was in the scanner room and, during the acquisitions, performed passive motion of the hand/wrist or the foot/ankle of the patients. Passive motion was performed at a rate of approximately 1.5-2 Hz. Care was taken to isolate the induced movement only to the area of interest. During rest, the neuroradiologist maintained a stable grasp of the extremity under examination in an attempt to attenuate or eliminate somatosensory cortical activation.

All blood oxygen level-dependent functional MR images were acquired with conventional structural imaging, including a volumetric axially acquired fast-spoiled gradient-recalled sequence with 1-mm isotropic resolution and axially acquired diffusion tensor imaging with either 15 or 25 noncolinear directions of encoding.

Paradigm delivery, including timing cues for the neuroradiologist who performed passive motions, was controlled by using the Esys-fMRI system (Invivo, Pewaukee, Winconsin). fMRI data were processed by using an FDA-approved software package (DynaSuite Neuro 3.0; Invivo) and using the clinical experience and judgment of the neuroradiologist to guide thresholding and coregistration.

All passive functional motions were performed by a fellowship-trained neuroradiologist (A.F.C., M.T.W., or A.S.). For passive motions, the examiner flexed and extended the patient's wrists and ankles. All images were processed and analyzed by 1 of 2 fellowship-trained neuroradiologists with an American Board of Radiology subspecialty certificate in neuroradiology and with additional training and clinical experience with functional MR imaging (A.F.C. or M.T.W.). The functional maps were evaluated while overlaid on fast-spoiled gradient-recalled images.

Evaluation of the functional activation and localization for this retrospective review was performed by review of the clinical reports and images from the functional MR imaging studies. Images from all the studies were evaluated retrospectively by a neuroradiologist to confirm the presence or absence of structural abnormalities that may have been associated with absent or ectopic cortical activation.

\section{Sedation for fMRI}

All sedation was supervised by pediatric anesthesiologists. The default sedation protocol involved general anesthesia with intravenous propofol administered at the lowest dose to keep the patient asleep after induction. Information regarding anesthesia, including the medications used for induction and maintenance, was recorded in the medical record.

\section{Statistical Analysis}

Data were collected in a spreadsheet (Excel version 14.4.2; Microsoft, Redmond, Washington) and analyzed by using SPSS version 21 (IBM, Aramonk, New York). Continuous variables were compared with a Student $t$ test, and discrete variables were compared with the Fisher exact test. A $P$ value of $<.05$ was considered significant.

\section{RESULTS}

We identified $62 \mathrm{fMRI}$ studies with passive motion performed on 56 anesthetized patients in the study time period (28 male, 28 female). The average ( \pm standard deviation) age at the time of study was $8.80 \pm 7.47$ years (range, 0.54 to 41.85 years; median, 7.6 years). No MR imaging-related complications were identified.

Of these 56 patients, 53 (95\%) underwent passive-motion fMRI because of seizures, and 3 had additional indications for passive-motion fMRI being a recurrent supratentorial ependymoma without report of seizure $(n=1)$, gait abnormality $(n=1)$, and worsening headache $(n=1)$. Of the 53 patients with seizure, 5 had tuberous sclerosis complex, 4 had a history of a tumor, 1 had hemimegalencephaly, 1 had Rasmussen encephalitis, and 1 had febrile infection-related epilepsy syndrome. Of the 4 patients with seizure and history of a tumor, 3 passive-motion fMRI scans were performed to evaluate postresection seizures. One patient had a new-onset seizure and a left medial frontal tumor, and fMRI was performed for surgical planning.

Passive motion of the upper extremities was performed in $61(98 \%)$ of the studies. Passive motion of the lower extremities was performed in 60 (97\%) of the studies; in 47 (78\%) of them, the lower-extremity passive movement was performed simultaneously for each side, and in 13 (22\%) of them, the lower-extremity passive motor movement was performed simultaneously.

Of the 119 iterations of upper-extremity passive motion, cortical activation was identified reliably 105 times $(88 \% ; P=.33$ versus upper extremity). Of these activations, 90 (86\%) were in an 

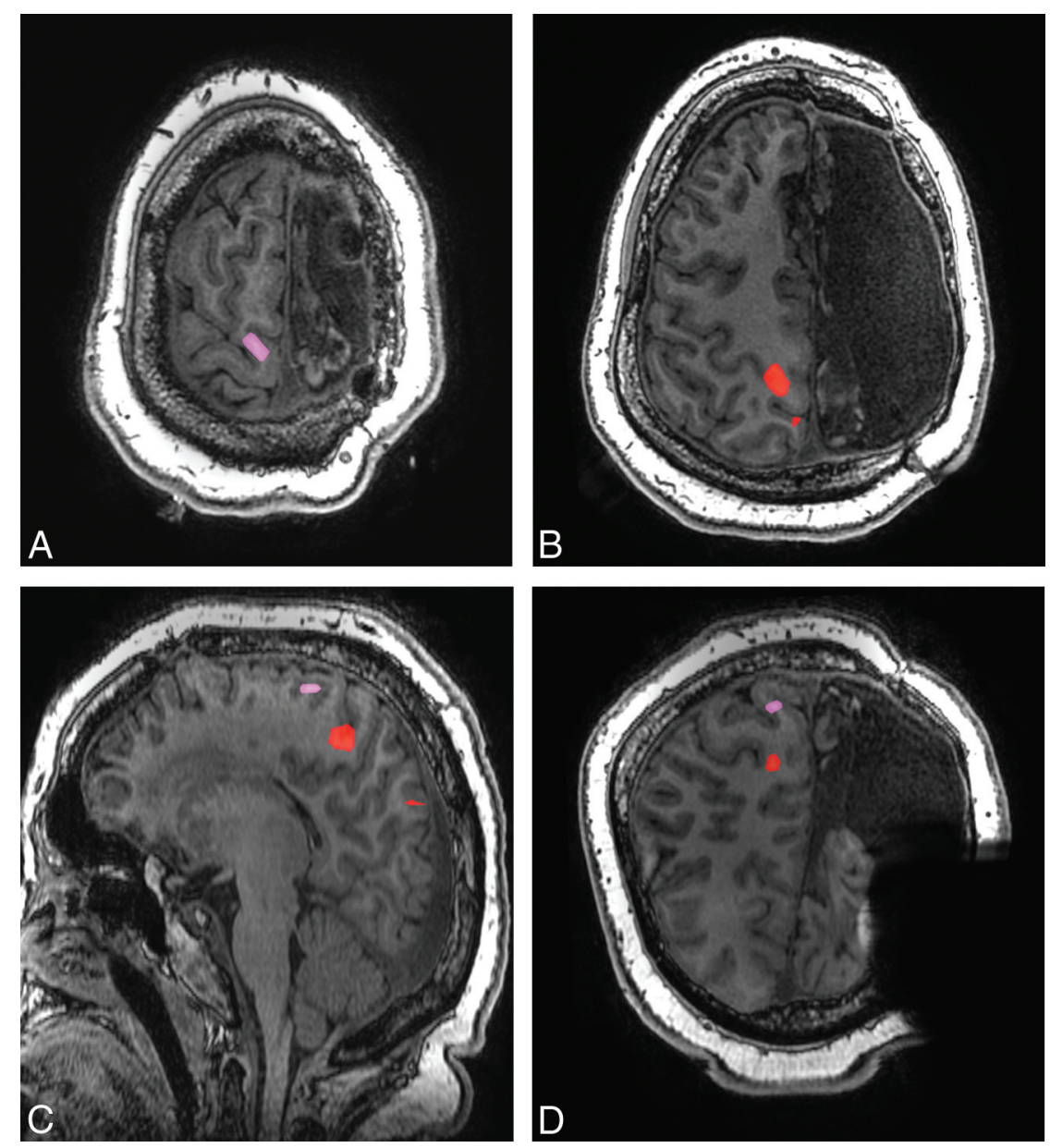

FIG 1. A, Axial fast-spoiled gradient-recalled image with overlay of cortical activation maps for passive movement of the left lower extremity (pink) in a 16-year-old girl with a history of leftsided functional hemispherectomy shows orthotopic cortical activation in the posterior/superior aspect of the right paracentral lobule. $B$, Activation maps for passive movement of the right lower extremity (red) are in a more posterior and inferior location in the right (ipsilateral) hemisphere. Parasagittal $(C)$ and coronal-oblique $(D)$ images show the relationship between the areas of activation for both lower extremities.

orthotopic location in the midportion of the precentral gyrus of the contralateral hemisphere. Three $(2.5 \%)$ iterations were in an ectopic location in the contralateral hemisphere, and $9(7.6 \%)$ were in an ectopic location in the ipsilateral hemisphere. Of the 119 iterations, there were no significant cortical activations in 14 (11.8\%).

Of the 118 iterations of lower-extremity passive motion, cortical activation was identified $86(73 \%)$ times. Of these, 82 $(94.5 \%)$ were in an orthotopic location in the superior portion of the precentral gyrus of the contralateral hemisphere, 1 $(1.2 \%)$ was in an ectopic location in the contralateral hemisphere, and $3(3.5 \%)$ were in an ectopic location in the ipsilateral hemisphere (Fig 1). Of the 13 iterations of bilateral lowerextremity passive motion, cortical activation was identified 9 (69.2\%) times in an orthotopic location in the superior portion of the precentral gyrus bilaterally. In the other $4(30.8 \%)$ iterations, there was no significant cortical activation. Of the 105 iterations in which lower-extremity passive motion was performed separately, there were $66(62.9 \%)$ times at which cortical activation was seen in an orthotopic location. One patient underwent passive motion for simultaneous evaluation of both lower extremities and isolated evaluation of the right lower extremity, with concordant identification of right lowerextremity cortical activation on the 2 paradigms. There were 4 (3.8\%) activations in ectopic locations. In the other $28(23.7 \%)$ of 118 iterations in which lower-extremity passive motion was performed separately, there was no significant cortical activation. Of the 118 total iterations of lowerextremity motion, there was no significant cortical activation in 32 (27.1\%).

The average age of the patients in whom no cortical activation was demonstrated in at least one upper extremity was $6.2 \pm 2.8$ years (range, 1.94-11.27 years; median, 6.51 years $[n=11]$ ), and the average age was $9.4 \pm 8.0$ years (range, $0.54-41.85$ years; median, 8.11 years $[n=51])$ for patients in whom the scans revealed bilateral cortical activation $(P=.21)$. The average age of the patients in whom no cortical activation was demonstrated in at least one lower extremity was $8.11 \pm 8.68$ years (range, $0.65-41.85$ years; median, 6.49 years $[n=24]$ ), and it was $9.2 \pm 6.7$ years (range, $0.54-30.4$ years; median, 8.49 years $[n=38])$ for patients in whom there was bilateral lower-extremity cortical activation $(P=.56)$.

There were 4 instances in which cortical activation was identified in the left upper extremity, but there was no significant cortical activation in the right upper extremity. In all 4 cases, there were parenchymal abnormalities in the left hemisphere in the expected location of right upper-extremity motion. These abnormalities included leftsided Rasmussen encephalitis, previous left-greater-than-right watershed ischemic injury, bilateral periventricular leukomalacia and porencephalic cysts, and tuberous sclerosis complex with left precentral gyrus dysplasia.

\section{Patients with 2 Passive-Motion fMRI Scans}

For 6 patients, passive-motion fMRI was performed on 2 separate occasions; 2 of these patients had tuberous sclerosis complex, 2 had refractory seizures, 1 had febrile infection-related epilepsy syndrome, and 1 had hemimegalencephaly and a history of functional hemispherectomy.

The scans were performed on the first patient with tuberous sclerosis complex 5 months apart, at 1.9 and 2.4 years of age. The initial study showed an orthotopic location for the right lower extremity, the left upper extremity, and the left lower extremity but did not identify right upper-extremity motor 

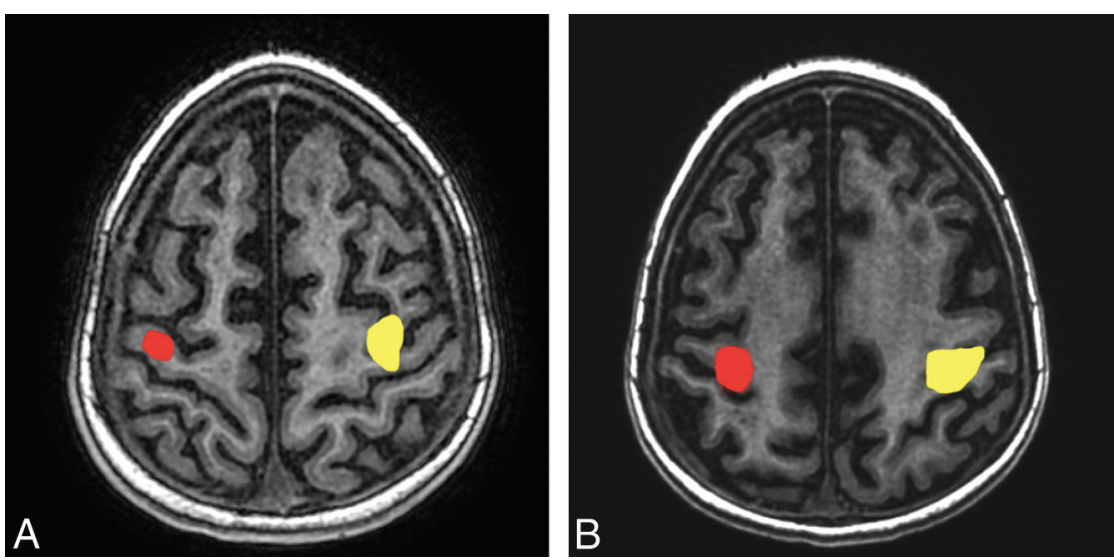

FIG 2. A, Axial fast-spoiled gradient-recalled image in a 1.4-year-old boy 6 weeks after initial presentation for febrile infection-related epilepsy syndrome. There was orthotopic localization of cortical activation from right (yellow) and left (red) upper-extremity passive movement. $B$, Axial fast-spoiled gradient-recalled image of the same patient at 1.6 years of age shows reidentification of orthotopic cortical activation from right (yellow) and left (red) upper-extremity passive movement in the setting of progressive parenchymal volume loss.

activation. The follow-up study revealed orthotopic motor cortex activation of all 4 extremities.

The scans of the second patient with tuberous sclerosis complex were performed at 0.5 and 1.5 years of age, before and after topectomy for an epileptogenic tuber. The initial and follow-up studies revealed orthotopic localization of all 4 extremities.

Two scans were performed on the patient with febrile infection-related epilepsy syndrome at 3-month intervals (at ages 1.4 and 1.6 years), during which time there was a progression of global parenchymal volume loss (Fig 2). The initial study was performed 6 weeks after the onset of symptoms. The initial and follow-up studies revealed orthotopic localization of all 4 extremities.

The patient with left-sided hemimegalencephaly had passivemotion fMRI scans at 1.7 and 3.1 years of age, and both scans showed orthotopic activation for the left upper and lower extremities and ipsilateral ectopic activation for the right upper and lower extremities.

One patient with refractory seizures had studies performed at 11.3 and 12.1 years of age. The first study showed orthotopic left lower-extremity activation and no significant activation on the other extremities. The second study showed orthotopic activation for the right and left upper and lower extremities.

The patient with refractory seizures had studies performed at 7.6 and 9.3 years of age, and both studies showed orthotopic activation for the right and left upper and lower extremities.

\section{Anesthesia}

Of 62 scans, 57 were performed with propofol as the anesthetic agent for induction and maintenance. Propofol and sevoflurane were used in 4 scans. One scan was performed with only sevoflurane. Cortical activation was identified in 179 of 217 (82.4\%) limbs evaluated in patients who received propofol anesthesia. Cortical activation was identified in 12 of 20 (60\%) limbs of the patients who received either propofol and sevoflurane or sevoflurane only $(P=.46$ versus propofol alone).

\section{Surgical Follow-Up}

Twelve patients underwent 15 surgical procedures after the passive-motion fMRI, including 3 tumor resections, 3 tuberectomies for tuberous sclerosis complex, 3 temporal lobectomies, 3 corpus callosotomies, 2 topectomies, and 1 frontal lobectomy. Two patients had more than 1 surgery. One patient with seizures that arose from right frontal encephalomalacia underwent a topectomy. There was incomplete seizure control, and after a second passive-motion $\mathrm{fMRI}$, the patient underwent a right frontal lobectomy, which resulted in the patient being seizure free at the 2 -month follow-up. One patient with tuberous sclerosis complex underwent 3 separate topectomies and had an fMRI before a right angular gyrus tuber resection, which resulted in 3 months of being seizure free. After a second passive-motion fMRI, the patient underwent a left frontopolar tuber resection, which resulted in 6 months of being seizure free. The patient subsequently underwent a left superior parietal lobule tuber resection and was seizure free for 6 months.

\section{DISCUSSION}

Functional MR imaging has been shown to be useful in presurgical planning because of its accuracy in localizing areas of cortical activation. It has aided neurosurgical planning by identifying eloquent cortex and its relationship to lesions that require resection. ${ }^{2,4,17,19,20,23,24}$ Early reports on passive-motion fMRI suggested using the known benefits of fMRI in uncooperative or very young patients. ${ }^{23,24}$ Additional studies have shown the activation with passive movement to correspond to the location of volitional movement. ${ }^{30}$ To our knowledge, this study involves the largest population in the existing literature on this subject. In addition, we demonstrated the ability to use passive-motion fMRI 13 times in patients younger than 2 years, the youngest of whom was 6 months of age.

One difference between passive and awake techniques is that awake patients can often trigger robust responses in not only the motor strip corresponding to upper- and lower-extremity movements but also the supplementary motor area. Similar activation in the supplementary motor area has been reported with active versus passive range-of-motion studies by using PET scans. ${ }^{31,32}$ Additional studies may include facial stimulation in the passive range-of-motion paradigm. An absence of cortical activation in right upper-extremity passive motion was seen in patients with a younger mean age than those in whom cortical activation was identified, suggesting that a young age could limit the success of passive-motion mapping. However, on an individual patient basis, passive motion was successful in a patient as young as 6 months old.

The most common fMRI indication in our group was intractable epilepsy in children who were being evaluated for all treat- 
ment options, including epilepsy surgery. The identification of motor cortex helps in the planning of any surgical procedure and when discussing the risks and benefits of surgery (combined with all of the other diagnostic test data, such as video-EEG, magnetoencephalography, transcranial magnetic stimulation, etc) with the parents. This information would help the clinicians and the family make the best decision about where surgery was ranked in the hierarchy of treatment options for their child.

One patient with a history of left functional hemispherectomy performed at 8 years of age for seizures related to posttraumatic encephalomalacia (Fig 1) showed evidence of remapping in the remaining hemisphere on an fMRI performed at 16 years of age. Passive motion of the right lower extremity revealed cortical activation within the right hemisphere. Similar results have been seen before. In a study in which passive-motion fMRI was performed on 8 patients who had undergone hemispherectomy, 2 patients were found to have undergone cortical remapping. ${ }^{33}$ Passive movement of the hand showed cortical activation in the ipsilateral hemisphere, a location similar to that for the contralateral hand. ${ }^{33}$

Imaging of another patient with a history of febrile infection-related epilepsy syndrome (Fig 2) revealed orthotopic cortical activation of all 4 extremities 6 weeks after initial presentation. Although follow-up imaging at 1.6 years of age showed significant cerebral atrophy, there was orthotopic localization of all 4 extremities. This case provides an example of fMRI demonstrating consistently accurate results despite progressive destruction of brain parenchyma. The utility of fMRI in structurally abnormal brains has also been discussed elsewhere. ${ }^{20,25}$ We did not have any patients who underwent passive-motion fMRI and later underwent awake fMRI, so we could not evaluate the concordance of the findings. There was a nonstatistical trend toward lower success in patients who did not have isolated propofol as the means of anesthesia, which corresponds with previous reports of sevoflurane being associated with lower success on passive-motion fMRI tasks. ${ }^{34}$ Passive motion of the lower extremities was successful less often than that of the upper extremities; however, this difference was not statistically significant.

Limitations in this study include our inability to confirm that the cortical activation was truly related to the specific function tested. Work has been done to compare invasive procedures such as intraoperative cortical stimulation mapping and the Wada test with other noninvasive modalities, including fMRI, magnetoencephalography, and transcranial magnetic stimulation. ${ }^{19,35-38}$ Other authors have used fMRI as the template to guide confirmatory intraoperative mapping ${ }^{2,9-}$ $11,17,39$; however, this was not feasible in this retrospective study. Because fMRI postprocessing is a computationally intensive process, results on the success of a paradigm are not known until after the anesthesia-based procedure is complete, which prevents the duplication of paradigms with spurious results or without appreciable cortical activation. In addition, it is not currently possible to separate motor cortical activation from sensory activation. Although this may not be a limiting factor for orthotopic perirolandic cortical activation, in which posterior extension is felt to be related to sensory activation, ectopic results may be more difficult to interpret. Passive facial motion and/or sensory paradigms have been measured with limited success in other studies; however, it was not evaluated in our patient population. ${ }^{24}$ Manual passive motion was performed in this study, but other studies have shown a pneumatically driven device to perform more reproducible passive movements. $^{24,40}$

Blood oxygen level-dependent fMRI has some benefits compared with the criterion standard, intraoperative cortical stimulation; it is noninvasive, it has superior spatial resolution, and it is not limited by the extent of craniotomy exposure. ${ }^{2,41}$ Passivemotion fMRI does share one similarity with intraoperative cortical stimulation in that results may be affected by depth of sedation. ${ }^{17}$ Compared with other noninvasive techniques such as electroencephalography and magnetoencephalography, blood oxygen level-dependent fMRI has a lower temporal resolution but a higher spatial resolution. Blood oxygen level-dependent fMRI depends on blood flow, and hemodynamic changes that follow neuronal activation are not identical in all patients. In addition, metabolically active brain tumors may lead to the incorrect impression of absence of cortical activation because of blood flow being redirected by the high oxygen demand of the tumor, a process known as neurovascular uncoupling. ${ }^{2,42,43}$ Studies have shown, however, that blood oxygen level-dependent fMRI is still a relatively reliable tool for cortical mapping, even in patients with brain tumors. ${ }^{2,4,17,19-21}$

Our study shows that passive-motion fMRI can localize upper-extremity motor cortex reliably and in most cases can identify lower-extremity motor cortex. This technique can be applied at any institution that performs task-based fMRI. Awareness of this technique can enable functional mapping to help guide treatment planning in young children with tumors and lesion-based epilepsy. In fact, fMRI performed without adjunct intraoperative cortical stimulation in awake patients has already been shown to enable neurosurgeons to be more aggressive in resection and to shorten time in the operating room, ${ }^{21}$ and no long-term neurologic deficits were observed in a study that involved 22 patients in whom fMRI was performed in adjunct with intraoperative cortical stimulation; in that study, there was an extremely high level of concordance between fMRI and intraoperative cortical stimulation mapping. ${ }^{44}$

\section{CONCLUSIONS}

Passive-motion fMRI is an effective tool for noninvasive motor mapping in patients who are too young or otherwise unable to comply with traditional noninvasive mapping, possibly providing a safer alternative (or adjunct) to intraoperative monitoring.

\section{REFERENCES}

1. Berger MS, Ojemann GA. Intraoperative brain mapping techniques in neuro-oncology. Stereotact Funct Neurosurg 1992;58:153-61 CrossRef Medline

2. Pillai J, Zaca D, Choudhri A. Clinical impact of integrated physiologic brain tumor imaging. Technol Cancer Res Treat 2010;9:359-80 CrossRef Medline

3. Wada J, Rasmussen T. Intracarotid injection of sodium amytal for

AJNR Am J Neuroradiol 36:1675-81 Sep 2015 www.ajnr.org

1679 
the lateralization of cerebral speech dominance. J Neurosurg 2007; 106:1117-33 CrossRef Medline

4. Papanicolaou AC, Rezaie R, Narayana S, et al. Is it time to replace the Wada test and put awake craniotomy to sleep? Epilepsia 2014;55: 629-32 CrossRef Medline

5. Bonelli SB, Powell RH, Yogarajah M, et al. Imaging memory in temporal lobe epilepsy: predicting the effects of temporal lobe resection. Brain 2010;133:1186-99 CrossRef Medline

6. Binder JR, Swanson SJ, Hammeke TA, et al. Determination of language dominance using functional MRI: a comparison with the Wada test. Neurology 1996;46:978-84 CrossRef Medline

7. Binder JR, Sabsevitz DS, Swanson SJ, et al. Use of preoperative functional MRI to predict verbal memory decline after temporal lobe epilepsy surgery. Epilepsia 2008;49:1377-94 CrossRef Medline

8. Cohen-Gadol AA, Westerveld M, Alvarez-Carilles J, et al. Intracarotid amytal memory test and hippocampal magnetic resonance imaging volumetry: validity of the Wada test as an indicator of hippocampal integrity among candidates for epilepsy surgery. $\mathrm{J} \mathrm{Neu}$ rosurg 2004;101:926-31 CrossRef Medline

9. Yetkin FZ, Hammeke TA, Swanson SJ, et al. A comparison of functional MR activation patterns during silent and audible language tasks. AJNR Am J Neuroradiol 1995;16:1087-92 Medline

10. Roux FE, Boulanouar K, Ranjeva JP, et al. Cortical intraoperative stimulation in brain tumors as a tool to evaluate spatial data from motor functional MRI. Invest Radiol 1999;34:225-29 CrossRef Medline

11. Roux FE, Boulanouar K, Ranjeva JP, et al. Usefulness of motor functional MRI correlated to cortical mapping in Rolandic low-grade astrocytomas. Acta Neurochir (Wien) 1999;141:71-79 CrossRef Medline

12. Hirsch J, Ruge MI, Kim KH, et al. An integrated functional magnetic resonance imaging procedure for preoperative mapping of cortical areas associated with tactile, motor, language, and visual functions. Neurosurgery 2000;47:711-21; discussion 721-22 CrossRef Medline

13. Binder JR, Swanson SJ, Sabsevitz DS, et al. A comparison of two fMRI methods for predicting verbal memory decline after left temporal lobectomy: language lateralization versus hippocampal activation asymmetry. Epilepsia 2010;51:618-26 CrossRef Medline

14. Genetti M, Tyrand R, Grouiller F, et al. Comparison of high gamma electrocorticography and fMRI with electrocortical stimulation for localization of somatosensory and language cortex. Clin Neurophysiol 2015;126:121-30 CrossRef Medline

15. Rosazza C, Aquino D, D'Incerti L, et al. Preoperative mapping of the sensorimotor cortex: comparative assessment of task-based and resting-state FMRI. PLoS One 2014:9:e98860 CrossRef Medline

16. Breier JI, Simos PG, Zouridakis G, et al. Language dominance determined by magnetic source imaging: a comparison with the Wada procedure. Neurology 1999;53:938-45 CrossRef Medline

17. Xie J, Chen XZ, Jiang T, et al. Preoperative blood oxygen level-dependent functional magnetic resonance imaging in patients with gliomas involving the motor cortical areas. Chin Med J 2008;121: 631-35 Medline

18. Hanakawa T, Ikeda A, Sadato N, et al. Functional mapping of human medial frontal motor areas: the combined use of functional magnetic resonance imaging and cortical stimulation. Exp Brain Res 2001;138:403-09 CrossRef Medline

19. Choudhri AF, Narayana S, Rezaie R, et al. Same day tri-modality functional brain mapping prior to resection of a lesion involving eloquent cortex: technical feasibility. Neuroradiol J 2013;26:548-54 CrossRef Medline

20. Chaudhary K, Kumaran SS, Chandra SP, et al. Mapping of cognitive functions in chronic intractable epilepsy: role of fMRI. Indian J Radiol Imaging 2014;24:51-56 CrossRef Medline

21. Petrella JR, Shah LM, Harris KM, et al. Preoperative functional MR imaging localization of language and motor areas: effect on therapeutic decision making in patients with potentially resectable brain tumors. Radiology 2006;240:793-802 CrossRef Medline
22. Peck KK, Bradbury M, Petrovich N, et al. Presurgical evaluation of language using functional magnetic resonance imaging in brain tumor patients with previous surgery. Neurosurgery 2009;64:644-53; discussion 652-53 CrossRef Medline

23. Li W, Wait SD, Ogg RJ, et al. Functional magnetic resonance imaging of the visual cortex performed in children under sedation to assist in presurgical planning. J Neurosurg Pediatr 2013;11:543-46 CrossRef Medline

24. Ogg RJ, Laningham FH, Clarke D, et al. Passive range of motion functional magnetic resonance imaging localizing sensorimotor cortex in sedated children. J Neurosurg Pediatr 2009;4:317-22 CrossRef Medline

25. Bigler ED. Magnetic resonance imaging in the evaluation of cognitive function. Pediatr Blood Cancer 2014;61:1724-28 CrossRef Medline

26. Yerys BE, Jankowski KF, Shook D, et al. The fMRI success rate of children and adolescents: typical development, epilepsy, attention deficit/hyperactivity disorder, and autism spectrum disorders. Hum Brain Mapp 2009;30:3426-35 CrossRef Medline

27. Rajagopal A, Byars A, Schapiro M, et al. Success rates for functional MR imaging in children. AJNR Am J Neuroradiol 2014;35:2319-25 CrossRef Medline

28. Guzzetta A, Staudt M, Petacchi E, et al. Brain representation of active and passive hand movements in children. Pediatr Res 2007;61: 485-90 CrossRef Medline

29. Weiller C, Jüptner M, Fellows $S$, et al. Brain representation of active and passive movements. Neuroimage 1996;4:105-10 CrossRef Medline

30. Kocak M, Ulmer JL, Sahin Ugurel M, et al. Motor homunculus: passive mapping in healthy volunteers by using functional MR imaging-initial results. Radiology 2009;251:485-92 CrossRef Medline

31. Mima T, Sadato N, Yazawa S, et al. Brain structures related to active and passive finger movements in man. Brain 1999;122:1989-97 CrossRef Medline

32. Lee CC, Jack CR Jr, Riederer SJ. Mapping of the central sulcus with functional MR: active versus passive activation tasks. AJNR Am J Neuroradiol 1998;19:847-52 Medline

33. Holloway V, Gadian DG, Vargha-Khadem F, et al. The reorganization of sensorimotor function in children after hemispherectomy: a functional MRI and somatosensory evoked potential study. Brain 2000;123:2432-44 CrossRef Medline

34. Bernal B, Grossman S, Gonzalez R, et al. FMRI under sedation: what is the best choice in children? J Clin Med Res 2012;4:363-70 CrossRef Medline

35. Picht T, Schmidt S, Brandt S, et al. Preoperative functional mapping for rolandic brain tumor surgery: comparison of navigated transcranial magnetic stimulation to direct cortical stimulation. Neurosurgery 2011;69:581-88; discussion 588 CrossRef Medline

36. Krieg SM, Sabih J, Bulubasova L, et al. Preoperative motor mapping by navigated transcranial magnetic brain stimulation improves outcome for motor eloquent lesions. Neuro-Oncology 2014;16: 1274-82 CrossRef Medline

37. Krieg SM, Sollmann N, Hauck T, et al. Repeated mapping of cortical language sites by preoperative navigated transcranial magnetic stimulation compared to repeated intraoperative DCS mapping in awake craniotomy. BMC Neurosci 2014;15:20 CrossRef Medline

38. Narayana S, Rezaie R, McAfee SS, et al. Assessing motor function in young children with transcranial magnetic stimulation. Pediatr Neurol 2015;52:94-103 CrossRef Medline

39. Meinzer M, Lindenberg R, Darkow R, et al. Transcranial direct current stimulation and simultaneous functional magnetic resonance imaging. J Vis Exp 2014;(86) CrossRef Medline

40. Shriver S, Knierim KE, O'Shea JP, et al. Pneumatically driven finger movement: a novel passive functional MR imaging technique for presurgical motor and sensory mapping. AJNR Am J Neuroradiol 2013;34:E5-7 CrossRef Medline 
41. Krings T, Schreckenberger M, Rohde V, et al. Functional MRI and 18F FDG-positron emission tomography for presurgical planning: comparison with electrical cortical stimulation. Acta Neurochir (Wien) 2002;144:889-99; discussion 899 CrossRef Medline

42. Holodny AI, Schulder M, Liu WC, et al. The effect of brain tumors on BOLD functional MR imaging activation in the adjacent motor cortex: implications for image-guided neurosurgery. AJNR Am J Neuroradiol 2000;21:1415-22 Medline
43. Pillai JJ, Mikulis DJ. Cerebrovascular reactivity mapping: an evolving standard for clinical functional imaging. AJNR Am J Neuroradiol 2015;36:7-13 CrossRef Medline

44. Roessler K, Donat M, Lanzenberger R, et al. Evaluation of preoperative high magnetic field motor functional MRI ( 3 Tesla) in glioma patients by navigated electrocortical stimulation and postoperative outcome. J Neurol Neurosurg Psychiatry 2005;76:1152-57 CrossRef Medline 